\title{
Iptek bagi Masyarakat untuk Melestarikan Kebudayaan Ketoprak dan Sholawat Pitutur Melalui Website Berbasis SEO Sebagai Media Informasi dan Promosi
}

\author{
Mardhiya Hayaty ${ }^{1}$, Arif Dwi Laksito ${ }^{2}$ \\ ${ }^{1,2}$ Informatika, Universitas AMIKOM Yogyakarta \\ ${ }^{1}$ mardhiya_hayati@amikom.ac.id, 2arif.laksito@amikom.co.id
}

\begin{abstract}
Ketoprak and sholawat pitutur began to dim with the development of the modern era. Folk art that became the cultural root of the village community Seyegan must continue to be preserved. To preserve the efforts made through the promotion through information technology media in this case the manufacture of SEO-based art sites (Search Engine Optimazation) for the existence of this art continues to grow with the local community and can be known by the public. The process of website creation begins with several designs such as web structure, layout, features available as well as the application of SEO on some articles. Promotion of folk art through the medium of information technology is expected to revive the arts ketoprak and sholawat as well as affect the welfare of members of the arts group.
\end{abstract}

Keywords: ketoprak, sholawat pitutur, search engine optimazation

\begin{abstract}
ABSTRAK
Kesenian Ketoprak dan sholawat pitutur mulai redup seiring dengan perkembangan jaman yang semakin modern. Kesenian rakyat yang menjadi akar budaya pada masyarakat desa Seyegan harus terus dilestarikan. Untuk melestarikannya dilakukan upaya-upaya melalui promosi melalui media teknologi informasi dalam hal ini pembuatan website kesenian berbasis SEO (Search Engine Optimazation) agar keberadaan kesenian ini terus tumbuh bersama masyarakat setempat dan dapat dikenal oleh masyarakat luas. Proses pembuatan website diawali dengan beberapa rancangan seperti struktur web, layout, fitur-fitur yang tersedia serta penerapan SEO pada beberapa artikel. Promosi kesenian rakyat melalui media teknologi informasi diharapkan mampu untuk menghidupkan kembali kesenian ketoprak dan sholawat serta berpengaruh terhadap kesejahteraan anggota-anggota dari group kesenian.
\end{abstract}

Kata kunci: ketoprak, sholawat pitutur, SEO

\section{PENDAHULUAN}

Desa Sayegan terletak di kelurahan Margokaton, kecamatan Sayegan, Kabupaten Sleman, daerah istimewa Yogyakarta, berjarak sekitar $17 \mathrm{~km}$ dari kota yogyakarta. Ditengah era globalisasi sekarang, desa ini masih menjunjung tinggi nilai kebudayaan sebagai warisan yang harus dilestarikan, ini terbukti masih adanya beberapa kelompok kesenian jawa seperti kesenian ketoprak dan shalawat.

Terdapat kelompok kesenian ketoprak di desa ini bernama "Dwi Mudo Budoyo" dan kelompok kesenian sholawat pitutur "Laras Wiromo". Anggota kelompok kesenian ini sebagian besar berasal dari masyarakat sekitar yang diwariskan secara turun temurun.

Besarnya dana yang harus disiapkan ketika akan melakukan pementasan seperti persewaan kostum, sound sistem, tenda, peralatan gamelan dan lain-lain. Hal tersebut disebabkan sebagian besar kelompok kesenian tidak memiliki peralatan dan kostum yang lengkap, harus menyewa dengan biaya yang mahal, sehingga pementasan jarang dilakukan dan memiliki pendapatan yang kurang menjanjikan bagi para anggota kesenian, selama ini pendanaan atas swadaya masyarakat di desa tersebut.

Kelompok kesenian belum pernah melakukan promosi berbasis teknologi tentang kesenian dan budaya desa sayegan sehingga kelompok kesenian desa ini tidak dikenal secara luas, hal ini dikarenakan kurangnya pengetahuan tentang teknologi informasi sebagai sarana promosi berbasis online dan berkurangnya kecintaan dan minat para generasi muda terhadap budaya dan kesenian tradisional, ini terlihat dari umur anggota kelompok kesenian mayoritas sudah lanjut usia. 
Tujuan dari pelaksanaan kegiatan ini adalah untuk melestarikan kesenian yang ada di daerah Seyegan melalui website sebagai sarana informasi dan promosi kepada masyarakat secara luas khususnya kesenian ketoprak dan sholawat pitutur yang telah ada sebelumnya.

\section{METODE PELAKSANAAN}

Metode pelaksanaa yang digunakan untuk mencapai tujuan-tujuan pelestarian tersebut adalah dengan melakukan kaderisasi anggota kelompok. Usia anggota kelompok banyak yang sudah lanjut usia sehingga dilakukan kaderisasi dari usia-usia lanjut usia ke usia-usia produktif. Hal ini dilakukan dengan cara latihan bersama antara anggota lama dengan yang baru, setelah itu diadakan sebuah pementasan ketoprak dan sholawat sebagai wujud nyata bahwa proses kaderisasi telah berhasil dilakukan.

Penggunaan website sebagai salah satu sarana untuk media promosi dan informasi memiliki peranan penting dalam era-globalisasi seperti sekarang ini. Hal ini bisa dilihat tingginya masyarakat Indonesia terhadap penggunaan internet.

\subsection{Penggunaan SEO (Search Engine Optimazition)}

SEO atau kepanjangan dari (Search Engine Optimization) adalah proses mempromosikan keberadaan situs web pada mesin pencari. Mesin pencari adalah sebuah program yang memungkinkan kita untuk mencari dokumen / konten berdasarkan kata kunci tertentu yang paling sesuai (Krrabaj \& Baxhaku 2017).

Optimalisasi search engine (SEO) adalah mengubah sebuah situs web untuk memperbaiki rangkingnya website di search engine populer seperti Google, Bing, dan Yahoo. Karena banyak pengunjung baru menemukan Situs web dan merek di mesin pencari populer. Penempatan di hasil pencarian untuk pencarian umum telah menjadi metode iklan yang kritis bagi banyak orang bisnis. Untuk mengoptimalkan penempatan situs web di mesin pencari yang populer, perlu memahami kriteria evaluasi yang digunakan oleh pencarian.(Zhang \& Cabage 2013)

SEO adalah suatu cara atau teknik untuk membuat situs atau blog kita berada pada halaman/posisi satu di mesin pencarian (search engine) seperti Google, Bing, dan Yahoo. Pengertian dari SEO juga sangat luas tetapi semuanya mencakup hal yang sama yaitu mengoptimisasi suatu halaman website/blog agar berada pada halaman/posisi satu di search engine dengan kata kunci yang ditarget.

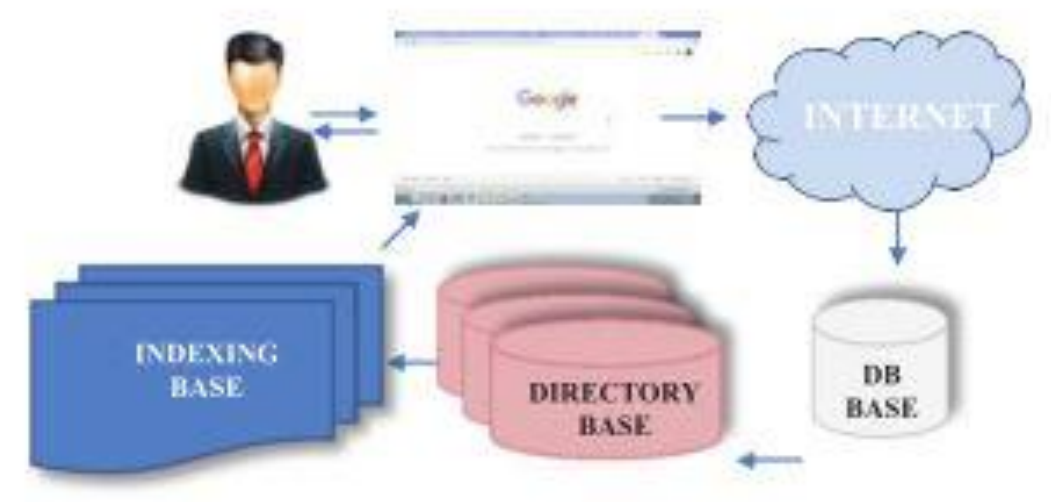

Gambar 1.Langkah mendapatkan hasil pencarian (Gupta et al. 2016)

Pada gambar 1 langkah pertama akan melibatkan pemprosesan query oleh mesin pencari, pada langkah selanjutnya teks dipetakan sesuai dengan keyword (kata kunci) yang relevan didalam database kemudian dialihkan ke direktori yang menyimpan baclink hasil pencarian, string query disesuaikan dengan kumpulan data dan dipetakan untuk hasil yang diharapkan. Indexs dibuat dengan peringkat yang ditentukan dan ditampilkan selama pencarian. Faktor sukses SEO adalah pemprosesan string dan pencocokan data dengan berbagai parameter yang tersedia. Parameter 
tersebut memainkan peranan besar dalam menentukan hit dan peringkat halaman pada mesin pencari atau search engine. (Gupta et al. 2016)

Secara umum proses optimasi SEO memiliki dua kelas utama, yang pertama adalah OnPage Optimazation dan Off-Page Optimazation. On-Page Optimazation berhubungan dengan struktur dan konten situs web dari pilihan kata hingga mekanisme indexs, sedangkan Off-Page Optimazation berhubungan dengan memasukkan external link masuk dan keluar.(Venkat N. Gudivada et al. 2015)

Berikut ini adalah teknik-teknik dalam mengoptimalkan SEO: 1) Pemilihan kata, pembuatan konten dengan pemilihan kata yang tepat, relevan dan berguna adalah persyaratan SEO yang mendasar. 2) Text URL, Penulisan URL yang relatif singkat tetapi bermakna lebih baik untuk halaman web 3) Konten Non-HTML, Untuk memastikan pengindexan yang efektif, sebagian besar konten harus dalam format HTML, namun konten selain text harus memuat informasi tambahan untuk memungkinkan pengindeksan.

\subsection{Penggunaan WordPress}

WordPress adalah sistem manajemen konten (CMS), yang ditulis dalam PHP, terutama digunakan untuk blogging. Meskipun statistik yang tepat sulit ditemukan, berbagai sumber menunjukkan bahwa WordPress digunakan di lebih dari 23,3\% dari 10 juta situs teratas, di atas 50\% dari semua situs CMS menjalankan WordPress, serta menyumbang sekitar 25\% dari semua situs web. Salah satu alasan popularitas WordPress adalah ekosistem plugin dan tema yang kaya yang tumbuh di sekitar platform WordPress, diaktifkan secara fleksibel.(Hills 2016)

WordPress menyertakan mekanisme plugin yang memungkinkan kode yang disediakan untuk dieksekusi sebagai respon atas kejadian sistem yang spesifik dan permintaan masukan / keluaran. Situs WordPress menyertakan koleksi plugin resmi yang di-host oleh WordPress. Kode untuk masing-masing plugin ini disimpan di repositori Subversion yang terletak di http://plugins.svn.wordpress.org/, dan setiap plugin resmi juga memiliki halaman web termasuk beberapa informasi dari repositori (misalnya, versi WordPress yang dibutuhkan untuk plugin) dan beberapa informasi yang dilacak langsung oleh WordPress (mis., jumlah unduhan). Repositori ini berisi total 54.512 plugin, 5 masing-masing ada di direktori terpisah di bawah root.

\subsection{Rancangan Struktur Web}

Dibawah ini merupakan struktur menu dan sub-menu dari content dari website yang akan digunakan sebagai media promosi mitra.

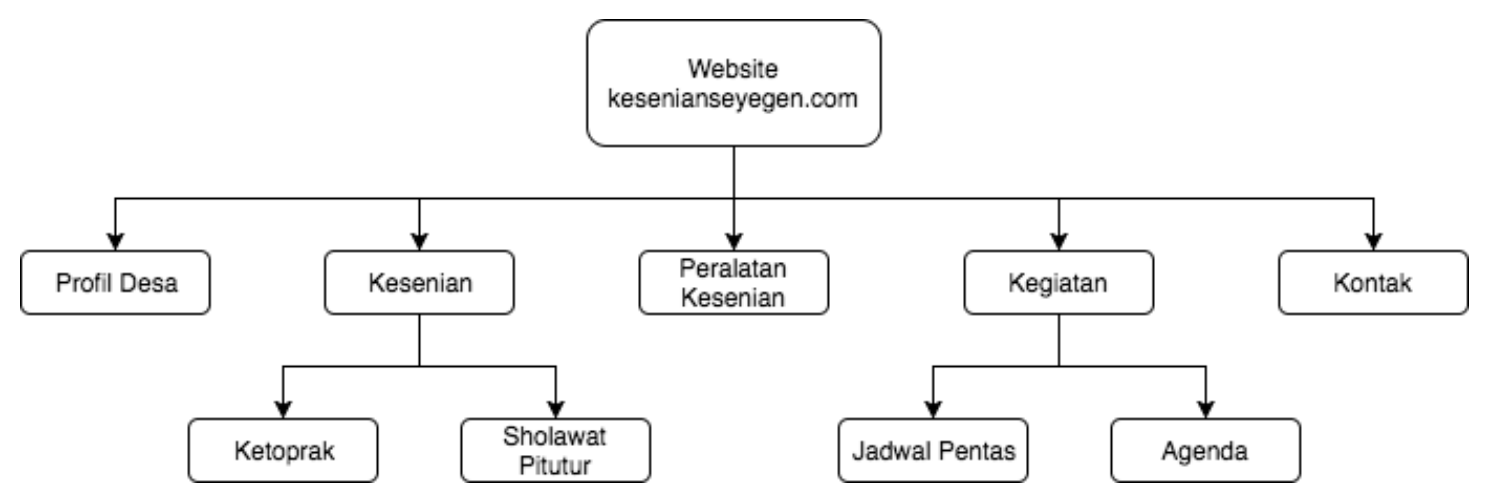

Gambar 2. Struktur menu website

Keterangan:

1. Home Website utama berisi seluruh content informasi yang akan ditampilkan saat pertama kali website diakses di alamat www.kesenianseyegan.com

2. Profil Desa, merupakan menu yang berisi informasi tentang desa seyegan

3. Kesenian, terdapat 2 sub-menu yaitu:

- Ketoprak, berisi informasi tentang kesenian Ketoprak di desa Seyegan 
- Sholawat Pitutur, berisi informasi tentang kesenian Sholawat Pitutur di desa Seyegan.

4. Peralatan Kesenian, menampilkan informasi alat-alat pendukung dalam kedua acara kesenian tersebut.

5. Kegiatan, terdapat 2 sub-menu yaitu:

- Jadwal Pentas, informasi pentas Ketoprak dan Sholawat Pitutur

- Agenda, informasi tentang agenda kegiatan acara kesenian

6. Kontak, informasi kontak person.

\subsection{Rancangan Content}

Dalam pengisian content akan dibedakan menjadi beberapa kriteria yaitu untuk artikel berita/informasi dan artikel yang melengkapi menu dari struktur pada rancangan diatas. Setiap content yang diisikan dapat berupa text, video, gambar ataupun suara. Khusus video dan suara menggunakan layanan pihak ketiga yang menyimpan data tersebut.

\subsection{Rancangan Layout}

Perancangan layout dilakukan untuk membuat kerangka website yang akan menampilkan beberapa informasi tentang kesenian di desa Seyegan tersebut. Dalam perancangan ini ditujukan untuk dua device yang akan mengakses website tersebut, yaitu: web browser dan mobile.

\subsubsection{Rancangan di Web Browser}

\section{TITLE WEB}

Sub Title
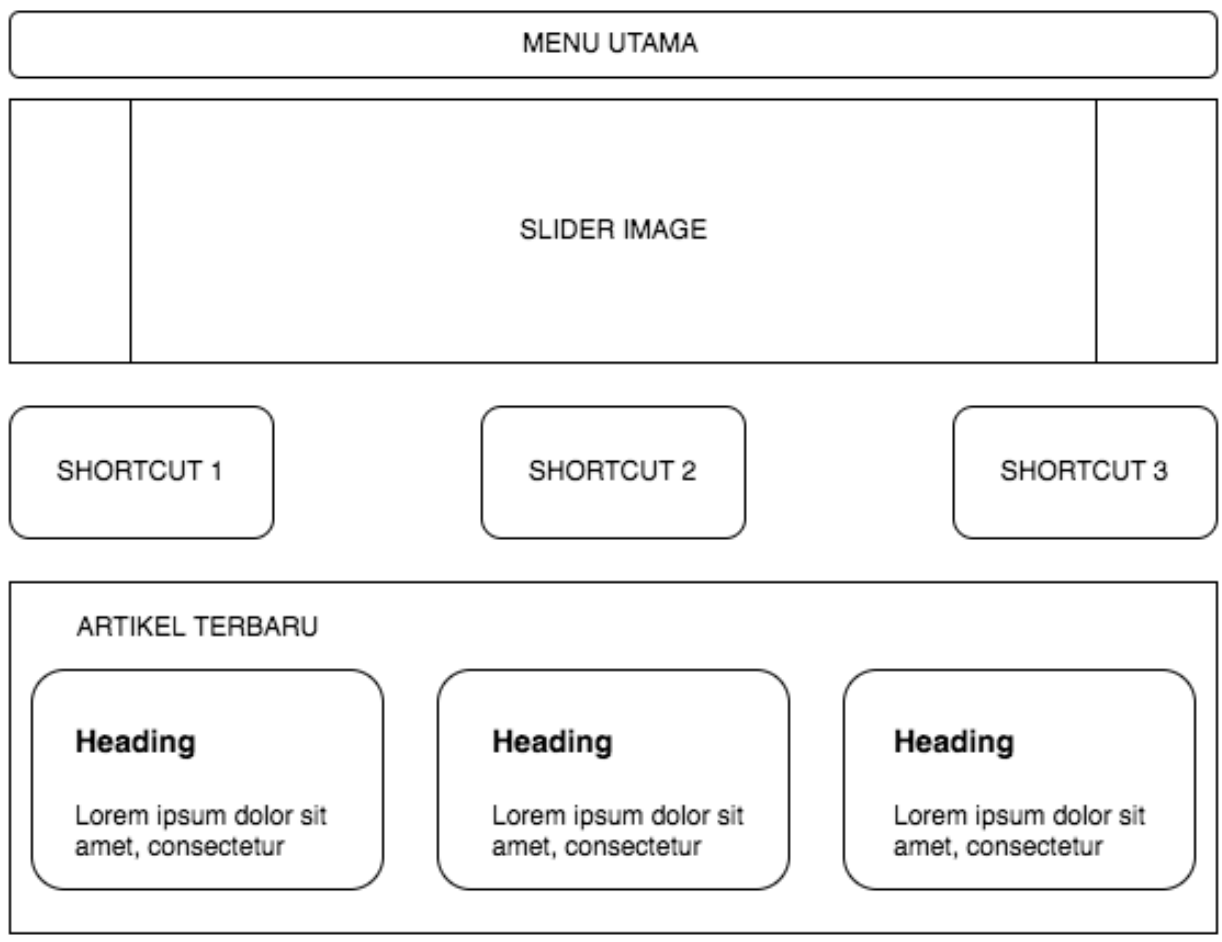

FOOTER

Gambar 3. Rancangan Web di browser 


\subsubsection{Rancangan di Mobile Phone}
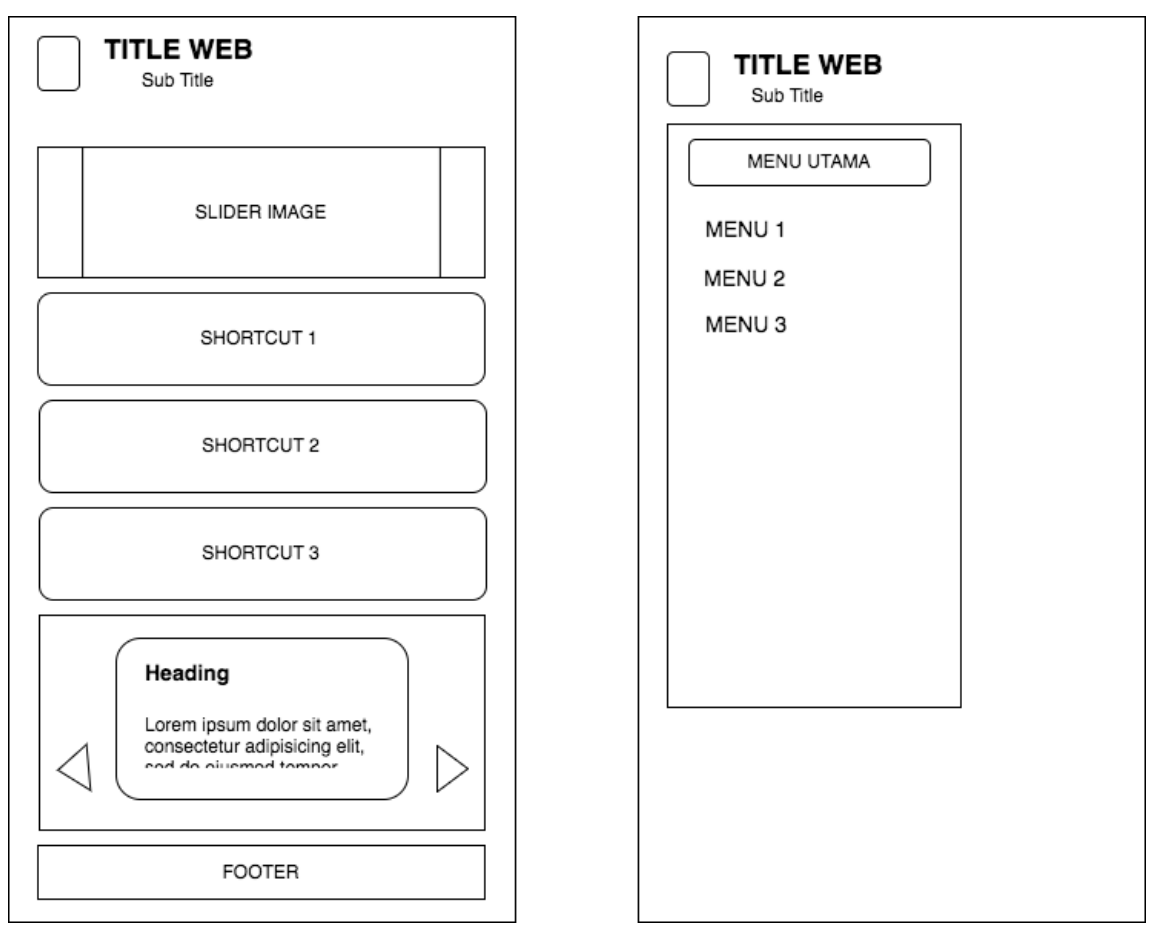

Gambar 4. Rancangan Web di Mobile Phone

Pada rancangan di mobile phone terdapat 2 konsep yaitu: pertama halaman utama yang menampilkan layout keseluruhan dan kedua menampilkan layout menu saat link menu utama dipilih dari halaman layout utama.

\section{HASIL DAN PEMBAHASAN}

Pada implementasinya telah dihasilkan suatu website menggunakan Wordpress, yaitu web CMS (Content Management System) yang dapat melakukan pengaturan menyeluruh terhadap content pada website tersebut. Untuk mendukung SEO disini digunakan plugin yaitu All in One SEO Pack. Dimana dengan menggunakan plugin tersebut pengguna diharapkan lebih mudah dalam menerapkan SEO pada website kesenianseyegan.com
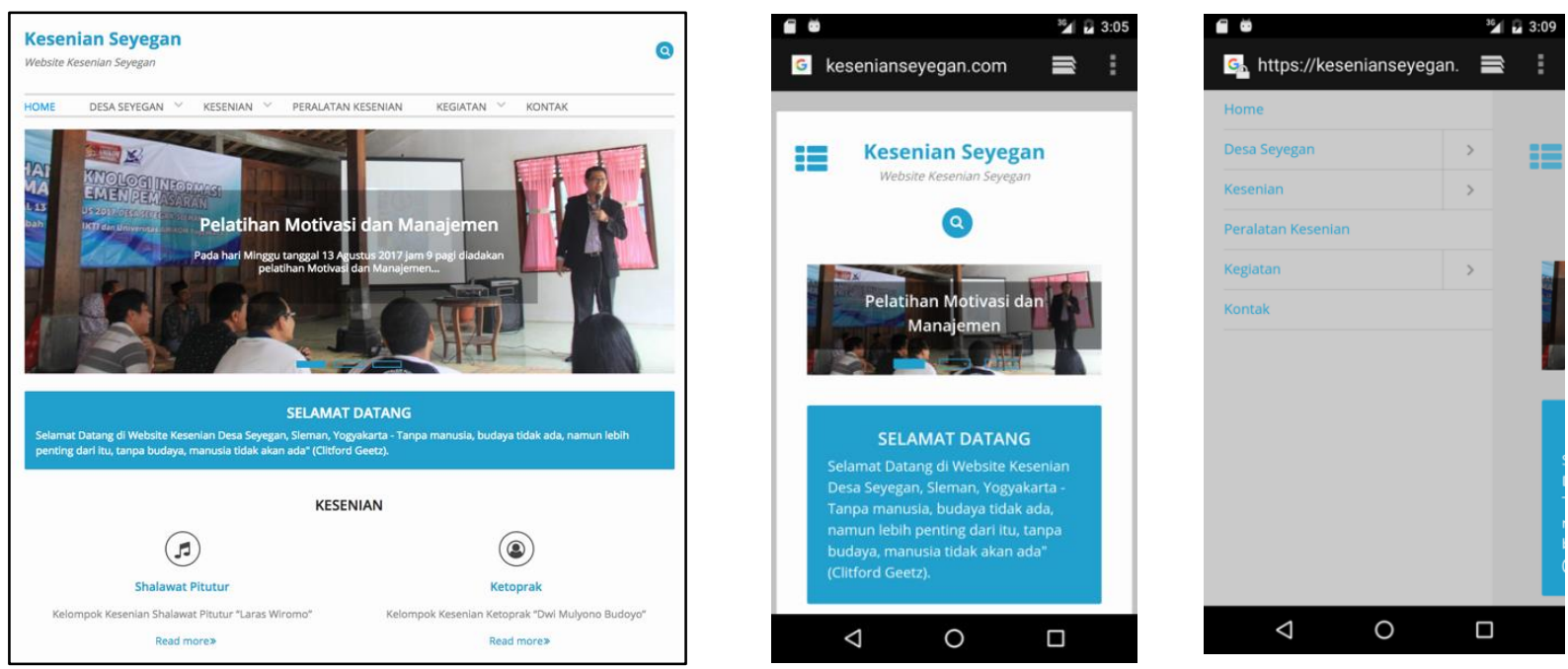

Gambar 5. Tampilan halaman web di PC dan Smartphone 
Gambar diatas adalah tampilan hasil implementasi website kesenianseyegan.com yang diakses melalui media browser di PC dan melalui browser di Smartphone. Pada gambar paling kanan, menunjukan menu yang ditampilkan pada tipe Smartphone lebih mudah dipahami oleh pengunjung karenan menggunakan style pada kebanyakan aplikasi di Smartphone.

Penerapan SEO menggunakan plugin di wordpress dapat diatur penggunaannya melalui halaman dashboard admin seperti pada gambar dibawah ini.

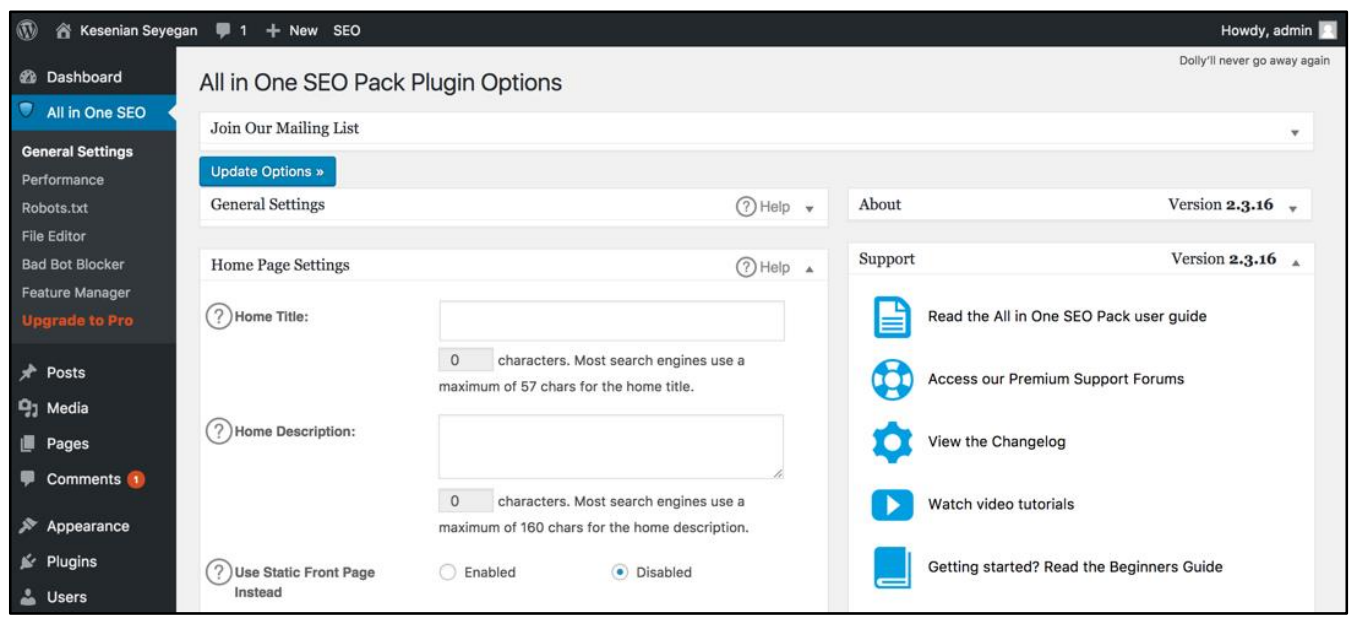

Gambar 6. Dashboard Admin dengan plugin SEO

Setelah adanya penambahan plugin SEO ini dalam waktu 1 bulan dalam pencarian di google menggunakan kata kunci "ketoprak+seyegan", "sholawat_seyegan" dan "kesenian+seyegan" menunjukan hasil pencarian tampil pada halaman pertama, meskipun belum berada di urutan teratas. Hasil pencarian seperti pada gambar di bawah ini,
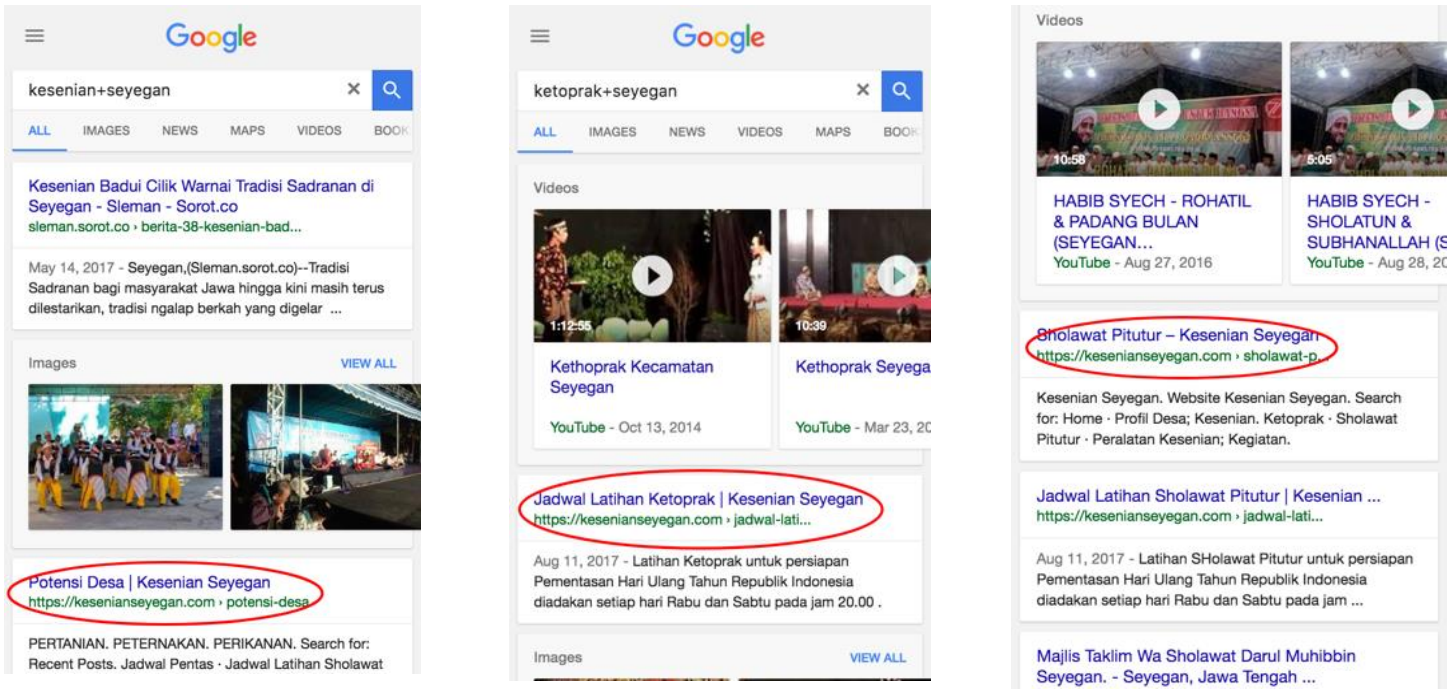

Gambar 7. Hasil pencarian di Google

\section{KESIMPULAN}

Seluruh kegiatan sudah dilakukan dimulai dari proses kaderisasi anggota kelompok kesenian dari anggota kelompok yang lanjut usia kepada anggota kelompok usia muda, dilakukan dengan latihan bersama untuk sebuah pementasan kesenian. Pembuatan website berbasis SEO telah menunjukkan hasil berada dihalaman pertama di mesin pencarian. Hal ini diharapkan 
meningkatkan promosi kesenain tersebut dan dalam jangka panjang kesenian ini dapat terus dilestarikan keberadaanya dan dapat mensejahterakan para anggota kelompok kesenian tersebut.

\section{UCAPAN TERIMA KASIH}

Kami selaku pelaksana kegiatan ini ingin memberikan ucapan terima kasih yang sebesar-besarnya kepada Kementrian Riset dan Teknologi sebagai penyandang dana hibah IbM bagi kesenian ketoprak dan sholawat pitutur di kelurahan Margokaton, Seyegan, Sleman, Daerah Istimewa Yogyakarta beserta Lembaga Penelitian Masyarakat Universitas AMIKOM Yogyakarta.

Terimakasih kepada jajaran perangkat desa Seyegan dan semua pihak yang telah membantu sehingga lancarnya proses pengabdian masyarakat ini.

\section{DAFTAR PUSTAKA}

Gupta, S. et al., (2016). Search Engine Optimization:Success Factors. Fourth International Conference on Parallel, Distributed and Grid Computing (PDGC), pp.3-7.

Hills, M., (2016). Navigating the WordPress Plugin Landscape. conference Austin, TX, USA 16-17 May 2016, pp.1-10.

Krrabaj, S. \& Baxhaku, F., (2017). Investigating Search Engine Optimization Techniques for Effective Ranking: A Case Study of an Educational Site. , (June), pp.13-16.

Venkat N. Gudivada, Rao, D. \& Pari, J., (2015). Understanding Search-Engine Optimization, Published by the IEEE Computer Society.

Zhang, S. \& Cabage, N., (2013). Does SEO Matter? Increasing Classroom Blog Visibility Through Search Engine Optimization. System Sciences (HICSS), 2013 46th Hawaii International Conference on 7-10 Jan. 2013 IEEE, pp.1610-1619. 
JPP IPTEK, November 2017, Vol. 1, No. 1

Halaman ini sengaja dikosongkan 